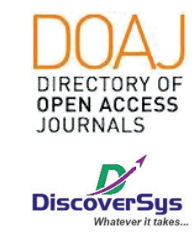

Published by DiscoverSys

\section{Faktor yang mempengaruhi kejadian asfiksia neonatorum di RSUD Wangaya Kota Denpasar}

\author{
Bella Kurnia, ${ }^{*}$ I Wayan Bikin Suryawan, A.A. Made Sucipta
}

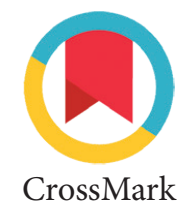

CrossMark

\title{
ABSTRACT
}

Background: Birth asphyxia is a serious clinical problem worldwide. There are many reasons a baby may not be able to take in enough oxygen before, during, or just after birth. Birth asphyxia is the inabiity of neonates to start breathing spontaniously right after birth.

Objective: This study was designed to assess the risk factors of birth asphyxia in neonates in Wangaya General Hospital.

Methods: It is a case control study. The data of the newborn and mother was retrospectively collected from medical record in Wangaya Regional General Hospital between November 2018 to March 2019. It uses consecutive sampling. Bivariate analysis using chi square and multivariate analysis using logistic regresssion.
Results: Bivariate analysis of risk factors of birth asphyxia that are studied are: low birth weight $p$ value 0.000 (OR: 30.118$)$; Number of birth $p$ value 0,013 (OR 4,025); Prematurity p value 0.001 (OR 18.286); PROM p value 0.751 (OR 1.508); preeclampsia p value 1.000 (OR 0.804); and Cesarean Section $p$ value 0.218 (OR 0.479). From multivariate analysis, the result was low birth weight $p$ value 0.020 ; number of birth $p$ value 0.003 ; prematurity $p$ value 0.766 ; caesarean section $p$ value 0,028 .

Conclusion: Risk factor of birth asphyxia in Wangaya General Hospital are low birth weight; number of birth (Primipara); and caesarean section.

Keyword: birth asphyxia, risk factors, denpasar, neonates

Cite This Article: Kurnia, B., Suryawan, I.W.B., Sucipta, A.A.M. 2020. Faktor yang mempengaruhi kejadian asfiksia neonatorum di RSUD Wangaya Kota Denpasar. Intisari Sains Medis 11(1): 378-381. D0I: 10.15562/ism.v11i1.548

ABSTRAK

Latar Belakang: Asfiksia neonatorum adalah suatu kondisi yang serius di seluruh dunia. Ada beberapa penyebab dimana bayi tidak bisa mendapatkan oksigen yang cukup sebelum, selama, atau setelah lahir. Asfiksia neonatorum adalah keadaan dimana neonatus tidak dapat memulai bernafas dengan spontan segera setelah lahr. Penelitian ini dilakukan untuk melihat faktor resiko terjadinya asfiksia neonatorum pada neonatus di RSUD Wangaya.

Metode: Penelitian ini adalah penelitian case control. Data neonatus dan data ibu diambil dari data rekam medis di RSUD Wangaya sejak November 2018 hingga Maret 2019. Studi ini menggunakan consecutive sampling. Analisa bivariat menggunakan chi square dan analisa multivariat menggunakan regressi logistik.

Hasil: Hasil dari analisa bivariat adalah: BBLR $p$ value 0,000 (OR: 30.118); Paritas $p$ value 0,013 (OR 4,025); Prematuritas $p$ value 0.001 (OR 18.286); KPD p value 0.751 (OR 1.508); Preeklampsia $p$ value 1.000 (OR 0.804); and Bedah Caesar $p$ value 0.218 (OR 0.479). Dari analisa multivariat, hasilnya adalah BBLR $p$ value 0.020 ; Paritas $p$ value 0.003 ; prematuritas $p$ value 0.766 ; bedah sesar $p$ value 0,028 .

Simpulan: Fakor resiko terjadinya asfiksia neonatorum di RSUD Wangaya adalah BBLR; Paritas (Primipara); and bedah sesar.
Departemen/SMF IImu Kesehatan Anak RSUD Wangaya, Denpasar, Bali

*Correspondence to: Bella Kurnia, Departemen/SMF IImu Kesehatan Anak RSUD Wangaya, Denpasar, Bali bellakurnia12@gmail.com

Diterima: 25-06-2019

Disetujui: 03-03-2020

Diterbitkan: 01-04-2020
Kata Kunci: Asfiksia neonatorum, faktor resiko, denpasar, neonatus

Cite Pasal Ini: Kurnia, B., Suryawan, I.W.B., Sucipta, A.A.M. 2020. Faktor yang mempengaruhi kejadian asfiksia neonatorum di RSUD Wangaya Kota Denpasar. Intisari Sains Medis 11(1): 378-381. D0I: 10.15562/ism.v11i1.548

\section{PENDAHULUAN}

Angka mortalitas neonatus adalah salah satu indikator yang menentukan derajat kesehatan anak. Berdasarkan World Health Organization (WHO), angka mortalitas neonatus adalah indikator pertama untuk status kesehatan anak; dan kurang lebih 3\% (3,6 juta) dari 120 juta neonatus mengalami asfiksia. Penyebab kematian neonatus utama di Indonesia adalah BBLR dan asfiksia. ${ }^{3}$ Asfiksia neonatorum adalah keadaan dimana bayi baru lahir (neonatus) tidak dapat memulai bernafas spontas saat setelah lahir. Asfiksia berkontribusi pada kematian neonatus sebanyak 8-35\% di negara maju dan 31-56,5\% di negara berkembang. ${ }^{1}$ Memiliki kadar oksigen yang terlalu rendah menyebabkan kerusakan otak dan akan menyebabkan komplikasi yang serius seperti kejang dan cerebral palsy. ${ }^{2}$ Ada beberapa fakotr yang menyebabkan asfiksia neonatorum. Faktor resiko tersebut dapat dibagi menjadi faktor 
ibu, bayi, dan tali pusat. Berdasarkan Nishat dkk, faktor resiko tersing dari asfiksia neonatorum adalah preeklampsia eklampsia, oligohidramnion, paritas, prematuritas dan IUGR. ${ }^{1}$ Sementara itu, menurut Martono dkk, fator resiko asfiksia neonatorum adalah perdarahan antepartum, preeklampsia, BBLR, prematuritas dan bedah caesar. ${ }^{4}$ Dan menurut Gilang dkk, penyebab tersering adalah BBLR, bedah caesar dan KPD. Berdasarkan penelitian di atas yang sebelumnya telah dilakukan, ada perbedaan fakotr resiko terjadinya asfiksia neonatorum di beberapa tempat yang berbeda; sebab dari itu, penulis ingin mengetahui faktor resiko asfiksia neonatorum di RSUD Wangaya, Denpasar.

\section{METODE}

Penelitian ini adalah penelitian observational analitik dengan design case control. Data-data secara restrospektif diambil dari rekam medis ibu dan bayi yang lahir di RSUD Wangaya dari November 2018 hingga Maret 2019. Penelitian ini terdiri dari 66 sampel. Pengambilan sampel dengan metode consecutive sampling. Data dari neonatus (berat badan lahir, usia gestasi, skor APGAR) dan data ibu (preeklampsia, KPD, metode persalinan dan jumlah persalinan) diambil dari rekam medis. Sampel penelitian kemudian dikelompokan menjadi bayi dengan asfiksia dengan bayi tanpa asfiksia. Bayi dengan asfiksia adalah semua bayi dengan skor APGAR $<7$ pada menit pertama kelahiran. Kriteria inklusi adalah seluruh bayi yang

Table 1 Karakteristik Sampel

\begin{tabular}{lc}
\hline Karakteristik & Frekuensi \\
\hline Laki-laki & $31(47 \%)$ \\
Perempuan & $35(53 \%)$ \\
Berat Badan Lahir Rendah & $17(25,8 \%)$ \\
Normal & $49(74,2 \%)$ \\
Primipara & $31(47 \%)$ \\
Multipara & $35(53 \%)$ \\
Prematur & $13(19,7 \%)$ \\
Aterm & $53(80,3 \%)$ \\
KPD & $12(18,2 \%)$ \\
Tidak KPD & $54(81,8 \%)$ \\
Preeclampsia & $11(16,7 \%)$ \\
Tidak Preeclampsia & $55(83,3 \%)$ \\
Bedah Sesar & $32(48,5 \%)$ \\
Per Vaginam & $34(51,5 \%)$ \\
Asfiksia & $33(50 \%)$ \\
Tidak Asfiksia & $33(50 \%)$ \\
\hline
\end{tabular}

lahir di RSUD Wangaya. Kriteria eksklusi adalah kelainan jantung bawaan, infeksi paru, bayi dari ibu HIV, dan bayi dengan kelainan kongenital. Data ditampilkan dalam bentuk tabulasi dan analisis data menggunakan SPSS for Mac. Analisis bivariat menggunakan chi square dan analisa multivariat menggunakan regressi logistik.

\section{HASIL}

Ada 66 bayi baru lahir yang didapatkan dari rekam medis sejak November 2018 hingga Mmaret 2019 yang memenuhi kriteria inklusi. Distribusi sampel dapat dilihat pada tabel 1 .

Pada tabel 2, dapat dilihat faktor- faktor mana saja yang bermakna. Analisa bivariat menggunakan chi square. Hasil dari analisis bivariat ini bila $p$ value $<0,25$ maka variabel tersebut akan lanjut ke tahap selanjutnya yaitu analisa multivariat dengan regresi logistik. Pada tabel 3 dapat dilihat hasil uji multivariat.

\section{PEMBAHASAN}

Asfiksia neonatorum ini adalah masalah yang paling sering ditemui di NICU. Asfiksia dapat menyebabkan morbiditas dan mortalitas yang tinggi karena berdampak pada kerusakan otak. Beberapa penelitian telah berupaya menelusuri insiden terjadinya asfiksia dan faktor resikonya. Pada penelitian ini, dapat dilihat BBLR merupakan faktor resiko terjadinya asfiksia neonatorum dengan nilai $\mathrm{p} 0.000$ pada analisa bivariat dan pada analisa multivariat p 0.020 dan memiliki 30x resiko daripada neonatus dengan berat normal (OR 30.118). Hasil ini sejalan dengan beberapa penelitian sebelumnya yang dilakukan oleh Gilang dkk (2010) denga p value 0,033 dan 0,003 (pada analisa multivariat); Lisa dkk (2016) dengan nilai p 0.000; dan Muthmainnah (2017) dengan nilai p 0,20 dan 0,012 pada analisis multivariat. Hasil ini sejalan dengan teori bahwa BBLR memiliki organ tubuh yang imatur termasuk paru-paru yang imatur sehingga menyebabkan insufisiensi surfaktan, reflek batuk, reflek menghisap dan menelan. Hal- hal tersebut berpengaruh dengan otot pernafasan tambahan yang lemah yang menyebabkan kesulitan bernafas. ${ }^{5}$

Pada penelitian ini dapat dilihat paritas merupakan faktor resiko terjadinya asfiksia neonatorum dengan nilai p 0,013 dan 0,003 (pada analisa multivariat) dan resikonya meningkat hingga $4 \mathrm{x}$ (OR 4,025). Hasil ini sesuai dengan penelitian dari Junita dkk (2013) denga nilai p 0,030; tetapi tidak sejalan dengan penelitian Gilang dkk dengan nilai p 0,757. Pada wanita primipara, otot uterus dan vagina masih kaku dan memiliki kontraksi 
Tabel 2 Hasil Analisa Bivariat

\begin{tabular}{|c|c|c|c|c|}
\hline & Asfiksia & Non Asfiksia & $P$ value & OR \\
\hline BBLR & $16(48,5 \%)$ & $1(3 \%)$ & 0,000 & 30,118 \\
\hline Normal & $17(51,51 \%)$ & $32(97 \%)$ & & \\
\hline Primipara & $21(63,6 \%)$ & $10(30,3 \%)$ & 0,013 & 4,025 \\
\hline Multipara & $12(36,4 \%)$ & $23(69,7 \%)$ & & \\
\hline Prematur & $12(36,4 \%)$ & $1(3 \%)$ & 0,001 & 18,286 \\
\hline Aterm & $21(63,6 \%)$ & $32(96,7)$ & & \\
\hline KPD & $7(21,2 \%)$ & $5(15,2 \%)$ & 0,751 & 1,508 \\
\hline Tidak KPD & $26(78,8 \%)$ & $28(84,8 \%)$ & & \\
\hline Preeclampsia & $5(15,2 \%)$ & $6(18,2 \%)$ & 1,000 & 0,804 \\
\hline Tidak Preeclampsia & $28(84,8)$ & $27(81,8)$ & & \\
\hline Cesarian Section & $19(57,6 \%)$ & $13(39,4 \%)$ & 0,218 & 0,479 \\
\hline Vaginal Delivery & $14(42,4 \%)$ & $20(60,6 \%)$ & & \\
\hline
\end{tabular}

Tabel 3 Hasil Analisa Multivariat

\begin{tabular}{|c|c|c|c|c|c|c|c|c|}
\hline \multirow[b]{3}{*}{ BBLR } & \multirow{3}{*}{$\frac{\text { B }}{3,622}$} & \multirow{3}{*}{$\begin{array}{c}\text { S.E. } \\
1,558\end{array}$} & \multirow{3}{*}{$\begin{array}{c}\text { Wald } \\
5,407\end{array}$} & \multirow{3}{*}{$\frac{\mathbf{d f}}{1}$} & \multirow{3}{*}{$\begin{array}{l}\text { Sig. } \\
, 020\end{array}$} & \multirow{2}{*}{\multicolumn{2}{|c|}{ Exp (B) Lower }} & \multirow{3}{*}{$\begin{array}{c}\text { 95\% CI for EXP (B) } \\
\text { Upper } \\
792,59\end{array}$} \\
\hline & & & & & & & & \\
\hline & & & & & & 37,417 & 1,766 & \\
\hline Primipara & 2,007 &, 678 & 8,761 & 1 &, 003 & 7,439 & 1,970 & 28,094 \\
\hline Prematur & ,466 & 1,563 & ,089 & 1 & ,766 & 1,594 &, 074 & 34,101 \\
\hline Metode Persalinan & $-1,693$ &, 772 & 4,812 & 1 &, 028 & ,184 &, 041 & 835 \\
\hline
\end{tabular}

yang lemah. Kontraksi yang lemah menyebabkan aliran darah berkurang ke uterus sehingga oksigen ke plasenta dan bayi menurun dan hal ini dapat menyebabkan asfiksia.

Prematuritas sebgai faktor resiko asfiksia neonatorum dengan $\mathrm{p}$ 0,001 pada analisa bivariat, tetapi bukan merupakan faktor resiko pada analisa multivariat dengan nilai $p$ 0,766. Hasil bivariat ini sejalan dengan Aminah (2015) dengan p 0,000 dan Martono p 0,000. Tetapi hasil ini tidak sejalan dengan analisa bivariat Gilang dengan p 0,458. Bayi prematur memiliki organ tubuh yang prematur juga termasuk paru-paru. Paru- paru prematur dengan/ tanpa kekurangan surfactan, akan menyebabkan asfiksia karena bayi kesulitan bernafas. ${ }^{6,7}$

Ketuban pecah dini (KPD) bukan merukan faktor resiko asfiksia neonatorum dengan nilai p 0,751. Hasil ini sejalan dengan penelitian dari Mutmainah dengan p 0,560 dan penelitain Martono p 0,226; tetapi hasil berlawanan dengan penelitan Gilang dkk dengan p 0,004 dan Fujiyarti (2014) dengan $\mathrm{p}$ 0,02. 50-75\% ibu dengan KPD akan melahirkan dalam 48 jam setelah terjadinya pecah ketuban, oleh sebab itu, hal tersebut akan mempengaruhi prematuritas dari bayi (bayi lahir sebelum waktunya), infeksi dan kompresi dari tali pusat yang dapat meningkatkan resiko asfiksia. ${ }^{8}$ Kelima, pada penelitian ini menunjukan preeklampsia bukan merupakan faktor resiko dengan nilai p 1,000. Hal ini sejalan dengan penelitian Gilang dengan nilai p 0,089; tetapi berlawanan dengan penelitian Martono dengan nilai p 0,000. Pada ibu dengan preeklampsia terjadi invasi tophoblastik abnormal dari kedua arteri desidual ibu. Hal ini dipercaya menyebabkan penurunan perfusi plasenta dan menyebabkan iskemia plasenta relatif. ${ }^{4}$

Metode persalinan merupakan faktor resiko terjadinya asfiksia dengan nilai p 0,218 pada analisa bivariat dan p 0,028 $(\mathrm{p}<0,05)$ pada analisa multivariat. Hal ini sejalan dengan penelitian Dian (2017) dengan nilai p 0,019; tetapi berlawanan dengan Muthmainnah dengan p 0,372. Pada studi ini ditemukan bahwa ibu yang melahirkan secara bedah sesar memiliki angka kejadian asfiksia lebih tinggi daripada persalinan pervaginam. Hal ini sejalan dengan teori bahwa bedah caesar mencegah terjadinya perubahan fisiologis paru-paru bayi baru lahir dimana paru-paru bayi selama di kandungan terisi air. Tekanan di dada bayi saat lewat jalan lahir ibu akan mengeluarkan cairan di paru. Setelah lahir, batuk bayi, akan mengeluarkan sisa cairan dari paru bayi. Pada bedah caesar, tidak adanya tekanan di dada bayi yang dapat mengeluarkan cairan dari paru bayi dan hal ini dapat menyebabkan kesulitan bernafas pada bayi dan sering disebut dengan tachypnea of newborn. ${ }^{9}$ 


\section{KESIMPULAN}

Dari penelitian ini, enam faktor resiko yang diteliti, terdapat tiga faktor resiko yang mempengaruhi kejadian asfiksia neonatorum di RSUD Wangaya. BBLR, Paritas, dan bedah sesar merupakan faktor resiko terjadinya asfiksia neonatorum di RSUD Wangaya, Kota Denpasar.

\section{ETHICAL CLEARANCE}

Penelitian ini sudah mendatap persetujuan dari Komisi Etik Penelitian Keehatan RSUD Wangaya Kota Denpasar, Nomor 05/KOM-ETIK/V/2019.

\section{KONFLIK KEPENTINGAN}

Penulis menyatakan bahwa tidak terdapat konflik kepentingan berhubungan dengan studi.

\section{PENDANAAN}

Penulis bertanggung jawab terhadap pembiayaan studi tanpa mendapat sponsor dari pihak manapun.

\section{KONTRIBUSI PENULIS}

Seluruh penulis berperan dan memiliki kontribusi terhadap penulisan laporan hasil studi meliputi analisis statistik, persiapan naskah, sintesis, maupun penyusunan draft penulisan.

\section{DAFTAR PUSTAKA}

1. Gilang, Notoatmodjo H, Rakhmawatie MD. Faktor- faktor yang berhubungan dengan kejadian asfiksia neonatorum (studi di rsud tugurejo semarang). Semarang: Fakultas Kedokteran Universitas Muhammadiyah Semarang; 2010. (https://jurnal.unimus.ac.id/index.php/kedokteran/ article/view/1300)

2. Majeed R, Memon Y, Majeed F, Shaikh NP, Rajar UD. Risk factors of birth asphyxia. J Ayub Med Coll Abbottabad; 2007.

3. Kemenkes RI. Untuk menurunkan angka kematian ibu dan kematian bayi perlu kerja keras. Jakarta: Ministry of Health Republic of Indonesia; 2010.

4. Utomo MT. Risk factors for birth asphyxia. Folia Medica Indonesiana; 2011. (http://journal.unair.ac.id/filerPDF/ 03\%2011023\%20MartonoE2\%20_format\%20FMI_pdf)

5. Ikatan Dokter Anak Indonesia (IDAI). Bayi berat lahir rendah. Dalam : standar pelayanan medis kesehatan anak. Ed I. Jakarta. 2004

6. Nugroho PMC. Tingkat keparahan asfiksia neonatorum pada bayi berat lahir rendah; 2015 .

7. Oktavionita V. Perbedaan angka kejadian risiko asfiksia neonatorum antara bayi kurang bulan denganbayi cukup bulan pada berat bayi lahir rendah (BBLR). Surakarta: Universitas Muhammadiyah; 2017.

8. Wiradharma. Kardana IM, Dharma AIW. Risiko asfiksia pada ketuban pecah dini di rsup sanglah. Sari Pediatri; 2013. (https://saripediatri.org/index.php/sari-pediatri/ article/view/339)

9. Fanny F. Sectio caesarea sebagai faktor risiko kejadian asfiksia neonatorum. Lampung: Fakultas Kedokteran Universitas Lampung; 2015.

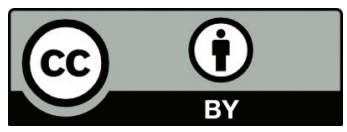

This work is licensed under a Creative Commons Attribution 